\title{
The Association Between Maternal Subclinical Hypothyroidism and Growth, Development, and Childhood Intelligence: A Meta-analysis
}

\author{
(D) Yahong Liư ${ }^{1}$, (D) Hui Chen², (D) Chen Jing ${ }^{3}$, (D) FuPin $\mathrm{Li}^{4}$ \\ ${ }^{1}$ The Second Hospital of Lanzhou University, Department of Pediatrics, Lanzhou, Gansu, China \\ ${ }^{2}$ The Second Hospital of Lanzhou University, Department of Endocrinology, Lanzhou, Gansu, China \\ ${ }^{3}$ Nanfang College of Sun Yat-sen University Faculty of Health and Nursing, Guangzhou, Guangdong, China \\ ${ }^{4}$ Gansu Provincial Maternity and Childcare Hospital, Lanzhou, Gansu, China
}

\begin{abstract}
What is already known on this topic?
Thyroid hormone plays an important role in the differentiation, development and maturation of tissues. Insufficiency or lack of thyroid hormones during pregnancy have a negative effect on fetal neurological and intellectual development. Many studies suggest that hypothyroidism in pregnancy can increase the risk of adverse outcomes of pregnancy. To this date, there is no established consensus on routine screening for subclinical hypothyroidism in pregnant women due to lack of credible evidence.
\end{abstract}

\section{What this study adds?}

Our meta-analysis showed that maternal subclinical hypothyroidism in pregnancy is associated with an increased risk of several adverse neonatal outcomes. Thus, it is necessary to assess thyroid function in pregnant women and intervene when necessary. Because of the high methodological quality of the included trials, our data provide supportive evidence for initiating further investigations.

\section{Abstract}

Objective: To explore the association between maternal subclinical hypothyroidism ( $\mathrm{SCH}$ ) in pregnancy and the somatic and intellectual development of their offspring.

Methods: Using RevMan 5.3 software, a meta-analysis of cohort studies published from inception to May 2017, focusing on the association between maternal SCH in pregnancy and childhood growth, development and intelligence, was performed. Sources included the Cochrane Library, Pub-Med, Web of Science, China National Knowledge Infrastructure and Wan Fang Data.

Results: Analysis of a total of 15 cohort studies involving 1.896 pregnant women with $\mathrm{SCH}$ revealed that SCH in pregnancy was significantly associated with the intelligence $(p=0.0007)$ and motor development $(p<0.00001)$ of the offspring. SCH was also significantly associated with the child's weight in four studies involving 222 women $(\mathrm{p}=0.02)$. Maternal SCH in pregnancy was identified as a risk factor for fetal growth restriction with a combined relative risk (RR) value of 2.4 [95\% confidence interval (CI): 1.56, 3.7]. Meta-analysis of 10 studies that provided numbers of preterm infants revealed a significant association between maternal SCH in pregnancy and premature delivery, with a combined RR of 1.96 (95\% CI: 1.34,2.88). There was a significant effect of maternal SCH in pregnancy on fetal distress in utero $(p=0.003)$.

Conclusion: Maternal SCH in pregnancy is associated with increased risk of adverse neonatal outcomes, including delayed intellectual and motor development, low birth weight, premature delivery, fetal distress and fetal growth restriction.

Keywords: Gestation, subclinical hypothyroidism, child development, meta-analysis 


\section{Introduction}

Thyroid hormone (TH) promotes growth via its effect on protein synthesis. It also plays an important role in differentiation, development and tissue maturation (1). TH is essential for brain cell proliferation. Prior to gestational week 20, TH-dependent brain development fully or partly depends on maternal TH $(2,3)$. Many studies provide evidence that hypothyroidism in pregnancy may increase the risk of adverse outcomes, including premature delivery, low birth weight (LBW), fetal demise and disrupted neurological/ intellectual development of the fetus $(4,5,6)$. Subclinical hypothyroidism $(\mathrm{SCH})$ is defined as an elevated serum thyroid stimulating hormone (TSH) level in the context of normal triiodothyronine $\left(\mathrm{T}_{3}\right)$ and tetraiodothyronine $\left(\mathrm{T}_{4}\right)$ levels $(7,8,9)$. Presence of $\mathrm{SCH}$ in pregnancy can be expected to have adverse effects on the growth and development of the fetus. In one survey, there was a higher incidence of maternal SCH in pregnancy (11.3\%) compared with clinical hypothyroidism in pregnancy $(2.4 \%)$ (10). Intelligence quotient scores in the offspring of women with untreated $\mathrm{SCH}$ were lower than those of the children of normal pregnant women (11). Currently, there is no consensus regarding routine $\mathrm{SCH}$ screening in pregnant women, owing to lack of credible evidence. Although many studies have investigated the effects of maternal $\mathrm{SCH}$ on childhood growth, development and intelligence level, the results have not been uniform. We therefore thought it would be worthwhile to conduct this meta-analysis of published studies to provide evidence-based research on the effects of maternal $\mathrm{SCH}$ on the growth, development and intelligence of the offspring.

\section{Methods}

This meta-analysis was based on the reports of domestic and international cohort studies that evaluated the effects of maternal $\mathrm{SCH}$ in pregnancy on childhood growth, development and intelligence. Only peer-reviewed articles published in English and Chinese were included in the analysis. The analysis only included studies on women with $\mathrm{SCH}$ in pregnancy with singleton fetuses. All subjects, apart from having $\mathrm{SCH}$, were otherwise healthy. Maternal $\mathrm{SCH}$ was defined as having a serum TSH level higher than the upper limit of pregnancy-specified reference value (the $97.5^{\text {th }}$ percentile of normal) and a serum free thyroxine $\left(\mathrm{FT}_{4}\right)$ level within normal range (between $2.5^{\text {th }}$ to $97.5^{\text {th }}$ percentiles of normal value) (12) or a TSH level between 2.5 and $10 \mathrm{mIU} / \mathrm{L}$ and a normal $\mathrm{FT}_{4}$ level according to the definition established by the American Thyroid Association
(13). All analyses were based on previous published studies, thus no ethical approval and patient consent are required.

We evaluated the following outcomes: growth; development and intelligence levels of the child (including growth, cognition and intelligence) measured by intelligence tests such as the Bayley Scales or the Gesell Scales. The Bayley Scales of Infant Development is one of the most psychometrically valid measurements for examining mental and psychomotor development in 1 to 30 monthsold infants. This test consists of a mental scale (163 items) and a psychomotor scale ( 81 items) used to assess cognitive development, including visual performance function, memory, first verbal outcomes and fine and gross motor development. Age at assessment-adjusted raw scores were centered to a mean of 100 with a standard deviation of 15 to calculate index scores (mental and psychomotor scores). Gesell Scales can reflect the development level of children from five aspects: gross motor quotient; fine motor quotient; adaptive behavior quotient; individual social behavior quotient; and language quotient. Birth weight (BW); LBW ( $\leq 2500 \mathrm{~g})$; premature birth ( $<37$ weeks gestation); intrauterine distress (variously defined); and fetal growth restriction (IUGR, variously defined) were also considered in the analysis.

The following studies were excluded: studies which included pregnant women treated with thyroxine; studies that did not include pregnant women with normal thyroid function as controls; non-cohort studies; publications containing duplicate data from the same study; studies for which the full text was not available; studies published only as abstracts; studies that did not provide initial data and did not respond to our requests for more information; and studies with inconsistent data.

Cochrane Library, Pub-Med, Web of Science, China National Knowledge Infrastructure and Wan Fang Data were searched from the inception of each database to May 2017 for relevant studies. Search words in Chinese included: pregnancy, gestation, $\mathrm{SCH}$, growth and development, intelligence; search words in English included pregnancy, pregnancies, gestation, $\mathrm{SCH}$, cognition, growth, intelligence, premature birth, premature delivery, premature labor, preterm delivery, preterm birth, preterm labor, fetal distress, intrauterine distress, fetal growth restriction. As an example, the specific search strategy for Pub-Med is shown in Table 1.

Two investigators worked independently to screen articles according to the inclusion and exclusion criteria. Disagreements were resolved by discussion with a third reviewer, also an expert in the field. Extracted data included authors, year of publication, sample size, gestational age 
at screening, intelligence score, BW, preterm delivery, intrauterine distress and fetal growth restriction.

The quality of selected studies was assessed independently by two investigators, using the Newcastle-Ottawa Scale (NOS) for cohort studies. The highest NOS score was 9 points, and consisted of the following three aspects: the definition and selection of subjects in the case and control groups (0-4 points); the comparability between study groups (0-2 points); and determination of exposure factors (0-3 points). A paper that scored $\geq 7$ points or more was considered "high-quality".

\section{Statistical Analysis}

Meta-analysis was performed with Rev Man software (edition 5.3). Qualitative and quantitative analyses were performed, and $95 \%$ confidence intervals (CI) $(95 \% \mathrm{CI})$ were calculated. Heterogeneity analysis was performed with the $\mathrm{I}^{2}$ test. Meta-analysis was performed with a fixed effect model for studies without heterogeneity $\left(\mathrm{I}^{2}<50 \%\right)$, and a random effect model for studies with heterogeneity $\left(I^{2} \geq 50 \%\right)$ after data combination (14). Descriptive analysis only was conducted for clinical trials with data not suitable for meta-analysis. Effect size was represented as relative risk (RR) for categorical variables and as standard mean difference for continuous variables, with $95 \% \mathrm{CI}$.

\section{Results}

A total of 1.176 articles were identified with the prespecified search strategy. Ultimately, 15 articles were included in the analysis after step-by-step screening $(5,10,15,16,17,18$, $19,20,21,22,23,24,25,26,27)$. The screening flow chart is shown in Figure 1.

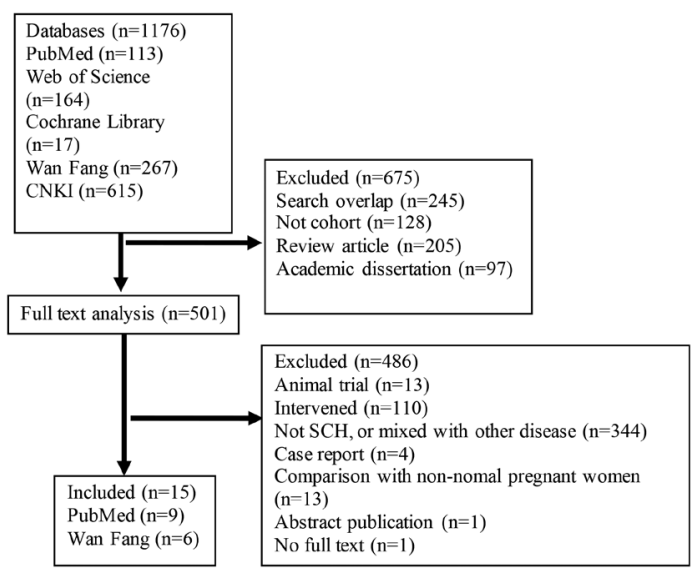

Figure 1. Flow chart of the article selection process

CNKI: China National Knowledge Infrastructure, SCH: subclinical hypothyroidism
Basic characteristics and quality evaluation of included studies: Of the 15 studies included, nine $(5,10,15,16,17,18,19,20,21)$ were published in English and the remaining six were published in Chinese. A total of 1.896 patients met the inclusion criteria and were included in the study, with 37.968 controls. Fetal intrauterine distress was reported in five studies $(17,19,20,22,27)$. The number of premature infants in various groups was reported in 10 studies $(5,10,15,16,19-22,26,27)$. Neonatal BW was reported in four studies $(10,19,24,26)$. The number of LBW neonates was reported in seven studies $(5,15,17,20,21,22,27)$. Childhood intelligence was measured at age 12 to 30 months in three studies $(18,24,25)$. In this meta-analysis, we chose cohort studies with high methodological quality. The principal characteristics and NOS scores are displayed in Table 2 and 3.

Maternal SCH in pregnancy and child intellectual and motor development: Because child intelligence and motor ability develop as children mature, studies with children of similar age were included in this meta-analysis (Table 4). In these three studies, the age range was 12 to 30 months. Intellectual and motor development were measured by Bayley Scales. The intellectual and motor development level of the children were compared between the $\mathrm{SCH}$ group and the control group. A fixed effect model was used because of the heterogeneity among studies $\left(p=0.17, I^{2}=47 \%\right)$. There was a significant association between maternal $\mathrm{SCH}$ in pregnancy and child intellectual development $(\mathrm{MD}=-6.08,95 \% \mathrm{CI}:-9.57 \sim-2.58, \mathrm{p}=0.0007)$ and child motor development $(\mathrm{MD}=-7.29,95 \% \mathrm{CI}:-10.30 \sim-4.28$, $\mathrm{p}<0.00001$ ).

The association between maternal $\mathrm{SCH}$ and BW: Data on BW were provided in four studies. The meta-analysis of these four studies revealed moderate heterogeneity $\left(p=0.11, I^{2}=50 \%\right)$. Thus, a fixed effect model was used. We found a significant effect of maternal $\mathrm{SCH}$ in pregnancy on BW (MD $=-0.27,95 \% \mathrm{CI}:-0.44 \sim-0.11, \mathrm{p}=0.001$ ) (Figure 2).

The association between maternal SCH and LBW: Data on LBW were provided in seven studies. We found moderate heterogeneity among them $\left(\mathrm{I}^{2}=58 \%\right)$. Thus, a random-effect model was used. Maternal SCH was a risk factor for LBW

\begin{tabular}{l}
\hline Table 1. PubMed search strategy \\
\hline \#1 Pregnancy OR pregnancies OR gestation \\
\#2 Subclinical hypothyroidism \\
\#3 \#1 AND \#2 \\
\#4 Cognition OR growth OR intelligence \\
\#5 Premature birth OR premature delivery OR premature labor \\
\#6 Preterm delivery OR preterm birth OR preterm labor \\
\hline
\end{tabular}


(combined RR: 1.78, $95 \%$ CI: 1.04-3.07, p=0.04). Figure 3A shows the association between maternal SCH and LBW. We also made a funnel plot as shown in Figure 3B. The funnel plot of this study is asymmetrical, indicating that there may be a publication bias.

The association between maternal $\mathrm{SCH}$ and fetal growth restriction: Data on fetal growth restriction was provided in three studies. The meta-analysis of these studies demonstrated a significant correlation between maternal $\mathrm{SCH}$ and fetal growth restriction, with no heterogeneity among results $\left(\mathrm{I}^{2}=0 \%\right)$. Thus, a fixed-effect model was used and determined a combined RR of 2.4 (95\% CI $(1.56,3.7)$, $p<0.0001$ ), as shown in Figure 4.

The association between maternal $\mathrm{SCH}$ and fetal intrauterine distress: Data on fetal distress were provided

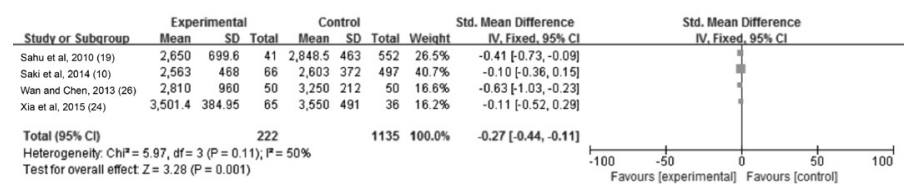

Figure 2. The forest plot of relative risk and $95 \%$ confidence interval of pooled studies comparing pregnant women with subclinical hypothyroidism to euthyroid pregnant women for risk of birth weight

SD: standard deviation, $\mathrm{CI}$ : confidence interval

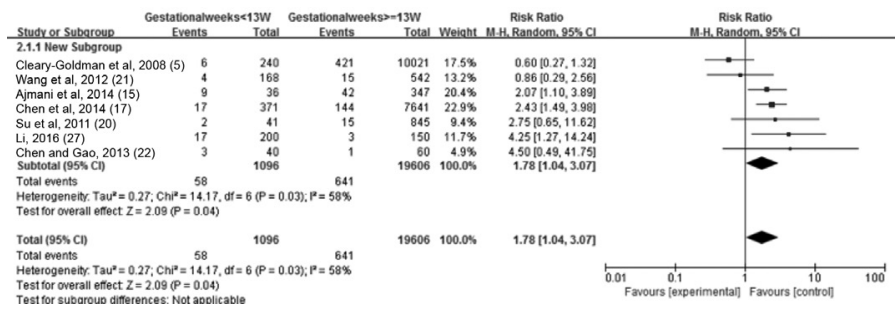

Figure 3A. The forest plot of relative risk and $95 \%$ confidence interval of pooled studies comparing pregnant women with subclinical hypothyroidism to euthyroid pregnant women for risk of low birth weight

$\mathrm{CI}$ : confidence interval

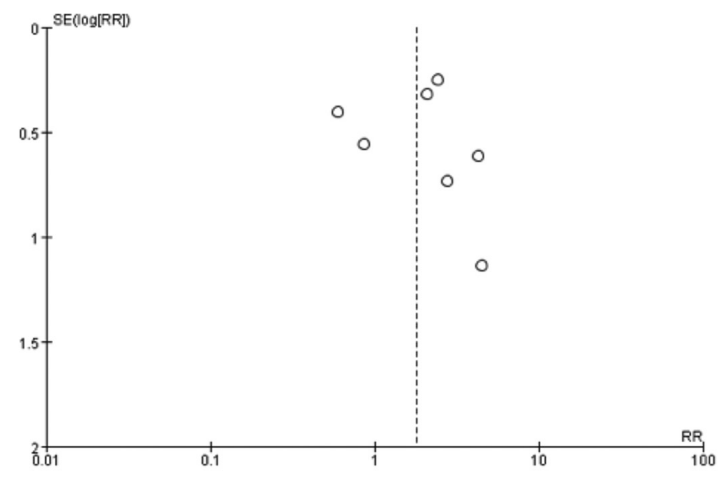

Figure 3B. The funnel plot of pooled studies comparing pregnant women with subclinical hypothyroidism to euthyroid pregnant women for risk of low birth weight

$\mathrm{RR}$ : relative risk

\begin{tabular}{|c|c|c|c|c|c|c|c|c|c|c|c|}
\hline \multirow{2}{*}{$\begin{array}{l}\text { Author } \\
\text { Ajmani et al (15) }\end{array}$} & \multirow{2}{*}{$\begin{array}{l}\text { Year } \\
2014\end{array}$} & \multirow{2}{*}{$\begin{array}{l}\text { Country } \\
\text { India }\end{array}$} & \multirow{2}{*}{$\begin{array}{l}\text { SCH definition } \\
\mathrm{TSH}>2.5 \mathrm{mIU} / \mathrm{mL}, \mathrm{FT}_{4} \text { normal }\end{array}$} & \multirow{2}{*}{$\begin{array}{l}\text { SCH/normal } \\
\text { (N) } \\
36 / 347\end{array}$} & \multirow{2}{*}{$\begin{array}{l}\text { GW } \\
13-26\end{array}$} & \multicolumn{6}{|c|}{ Outcomes } \\
\hline & & & & & & & & $\mathrm{C}$ & $\mathrm{D}$ & & $\mathrm{F}$ \\
\hline Casey et al (16) & 2005 & USA & $\begin{array}{l}\text { TSH }>97.5^{\text {th }} \text { percentile, } \mathrm{FT}_{4} \\
<0.680 \mathrm{ng} / \mathrm{dL}\end{array}$ & $404 / 16894$ & $<20$ & & & & $\mathrm{D}$ & & \\
\hline Chen et al (18) & 2015 & China & $\mathrm{TSH}>97.5^{\text {th }}$ percentile, $\mathrm{FT}_{4}$ normal & $106 / 106$ & $12-24$ & A & & & & & \\
\hline Chen et al (17) & 2014 & China & $\mathrm{TSH}>97.5^{\text {th }}$ percentile, $\mathrm{FT}_{4}$ normal & $371 / 7641$ & $10-17$ & & & C & & E & $\mathrm{F}$ \\
\hline $\begin{array}{l}\text { Cleary-Goldman et } \\
\text { al (5) }\end{array}$ & 2008 & USA & $\begin{array}{l}\text { TSH }>97.5^{\text {th }} \text { percentile, } \mathrm{FT}_{4} \\
2.5^{\text {th }}-97.5^{\text {th }}\end{array}$ & $240 / 10021$ & $10-13$ & & & $\mathrm{C}$ & $\mathrm{D}$ & & \\
\hline Sahu et al (19) & 2010 & India & $\mathrm{TSH}>5.5 \mathrm{mIU} / \mathrm{L}, \mathrm{FT}_{4}$ normal & $41 / 552$ & $13-26$ & & B & & $\mathrm{D}$ & E & \\
\hline Saki et al (10) & 2014 & Iran & $\mathrm{TSH}>97.5^{\text {th }}$ percentile, $\mathrm{FT}_{4}$ normal & $66 / 497$ & $15-28$ & & B & & $\mathrm{D}$ & & $\mathrm{F}$ \\
\hline Su et al (20) & 2011 & China & $\mathrm{TSH}>95^{\text {th }}$ percentile, $\mathrm{FT}_{4}=5-95^{\text {th }}$ & $41 / 845$ & $\leq 20$ & & & $\mathrm{C}$ & $\mathrm{D}$ & E & \\
\hline Wang et al (21) & 2012 & China & $\mathrm{TSH}>2.5 \mathrm{mIU} / \mathrm{L}, \mathrm{FT}_{4}$ normal & $168 / 542$ & $\leq 12$ & & & $\mathrm{C}$ & $\mathrm{D}$ & & \\
\hline Xia et al (24) & 2015 & China & $\mathrm{TSH}>3.5 \mathrm{mIU} / \mathrm{L}, \mathrm{FT}_{4}$ normal & $65 / 36$ & $\leq 12$ & A & B & & & & \\
\hline Li et al (23) & 2015 & China & $\mathrm{TSH}>5.12 \mathrm{mIU} / \mathrm{L}, \mathrm{FT}_{4}$ normal & $50 / 51$ & $<12$ & A & & & & & \\
\hline $\operatorname{Li}(27)$ & 2016 & China & $\mathrm{TSH}>2.5 \mathrm{mIU} / \mathrm{L}, \mathrm{FT}_{4}$ normal & $200 / 150$ & $38-41$ & & & $\mathrm{C}$ & $\mathrm{D}$ & E & \\
\hline Chen and Gao (22) & 2013 & China & $\mathrm{TSH}>2.5 \mathrm{mIU} / \mathrm{L}, \mathrm{FT}_{4}$ normal & $40 / 60$ & unknow & & & C & $\mathrm{D}$ & E & \\
\hline Li et al (25) & 2008 & China & $\mathrm{TSH}>4.2 \mathrm{mIU} / \mathrm{L}, \mathrm{FT}_{4}$ normal & $18 / 176$ & $16-20$ & A & & & & & \\
\hline Wan and Chen (26) & 2013 & China & $\mathrm{TSH}>2.5-10 \mathrm{mIU} / \mathrm{L}, \mathrm{FT}_{4}$ normal & $50 / 50$ & $5-20$ & & B & & $\mathrm{D}$ & & \\
\hline
\end{tabular}

SCH: subclinical hypothyroidism, GW: gestational weeks, TSH: thyroid stimulating hormone, $\mathrm{FT}_{4}$ : tetraiodothyronine

Outcomes; A: intelligence and growth; B: birth weight; C: low birth weight; D: preterm labor; E: intrauterine distress; F: fetal growth restrictriction 


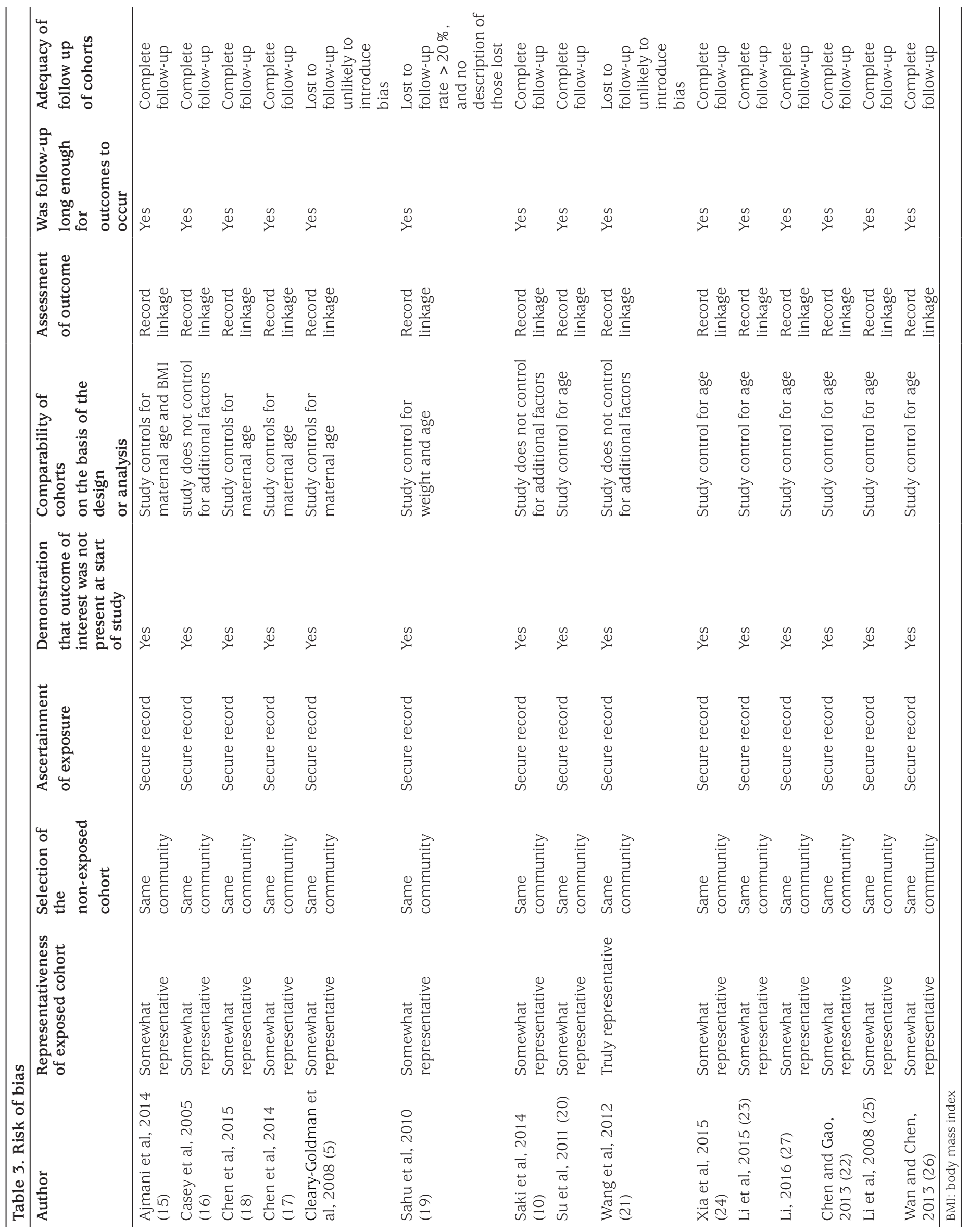


Table 4. Pooled relative risk with $95 \%$ confidence interval comparing pregnant women with subclinical hypothyroidism to pregnant euthyroid women

\begin{tabular}{lllll}
\hline Outcomes & $\mathrm{I}^{2}$ & $\mathrm{p}$ & Pooled RR [95\% CI] & Studies \\
\hline MDI & $47 \%$ & 0.0007 & $-6.08[-9.57 \sim-2.58]$ & $(18,24,25)$ \\
PDI & $47 \%$ & $<0.00001$ & $-7.29[-10.30 \sim-4.28]$ & $(18,24,25)$ \\
BW & $50 \%$ & 0.001 & $-0.27[-0.44 \sim-0.11]$ & $(10,19,24,26)$ \\
LBW & $58 \%$ & 0.04 & $1.78[1.04-3.07]$ & $(5,15,17,20,21,22,27)$ \\
Preterm labor & $61 \%$ & 0.0006 & $1.96[1.34-2.88]$ & $(5,10,15,16,19,20,21,22,26,27)$ \\
IUGR & $0 \%$ & $<0.0001$ & $2.4[1.56-3.7]$ & $(10,15,17)$ \\
Fetal distress & $20 \%$ & 0.003 & $1.66[1.19-2.31]$ & $(17,19,20,22,27)$ \\
\hline
\end{tabular}

RR: relative risk, MDI: Mental Developmental Index, PDI: Psychomotor Developmental Index, BW: birth weight, LBW: low birth weight, IUGR: intrauterine growth restriction, CI: confidence interval

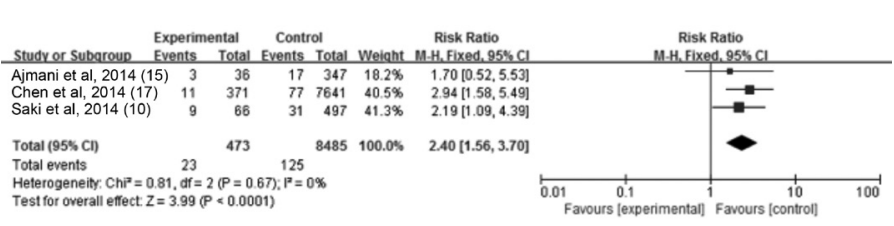

Figure 4 . The forest plot of relative risk and $95 \%$ confidence of pooled studies comparing pregnant women with subclinical hypothyroidism to euthyroid pregnant women for risk of fetal growth restriction

CI: confidence interval

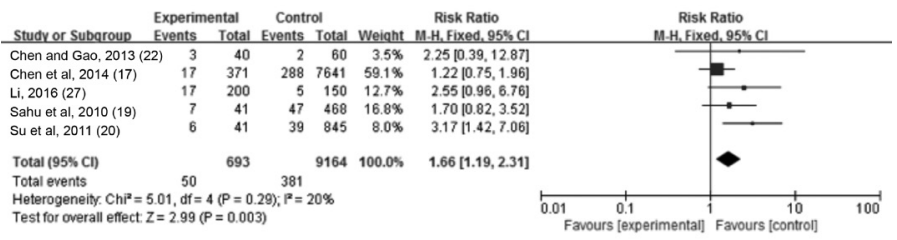

Figure 5. The forest plot of relative risk and $95 \%$ confidence interval of pooled studies comparing pregnant women with subclinical hypothyroidism to euthyroid pregnant women for risk of fetal intrauterine distress

\section{CI: confidence interval}

in five studies. Meta-analysis of these studies showed minor heterogeneity among results $\left(\mathrm{I}^{2}=20 \%\right)$. Thus, a fixed-effect model was used and demonstrated a combined RR of 1.66 [95\% CI $(1.19,2.31), p=0.003]$, as shown in Figure 5.

\section{The association between maternal $\mathrm{SCH}$ and premature}

delivery: Data on the number of preterm and term infants were provided in ten studies. Meta-analysis of these studies revealed moderate heterogeneity ( $\left.\mathrm{p}=0.006, \mathrm{I}^{2}=61 \%\right)$. Thus, a random-effect model was used and demonstrated a combined RR of 1.96 [95\% CI (1.34, 2.88), p=0.0006]. The forest plot and funnel forest plot are displayed in Figure $6 \mathrm{~A}$ and $6 \mathrm{~B}$. The funnel plot of this study is symmetrical, indicating that there is no publication bias.

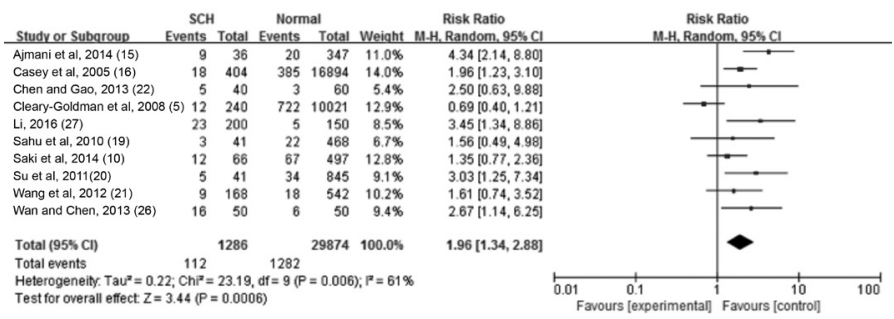

Figure 6A. The forest plot of relative risk and $95 \%$ confidence interval of pooled studies comparing pregnant women with subclinical hypothyroidism to euthyroid pregnant women for risk of premature delivery

CI: confidence interval

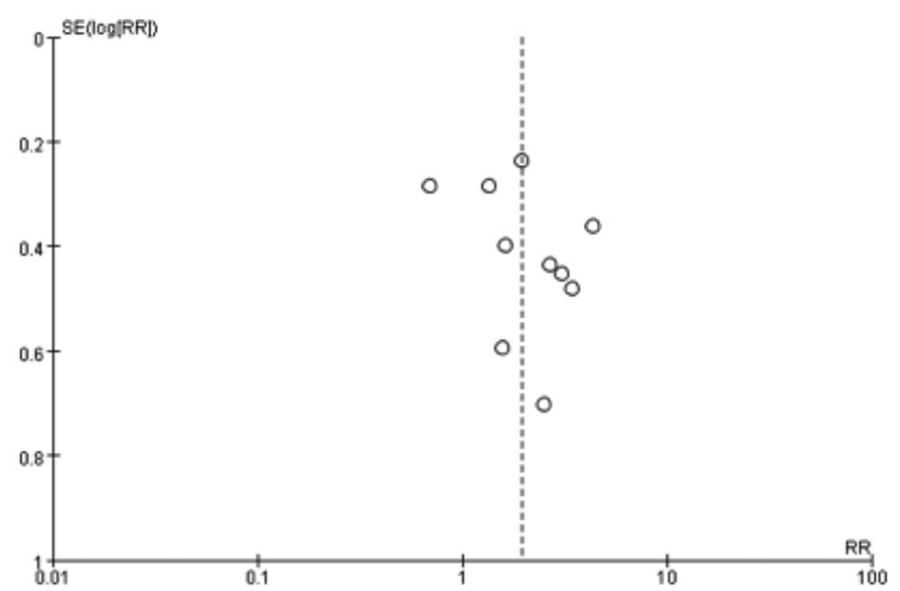

Figure 6B. The funnel plot of pooled studies comparing pregnant women with subclinical hypothyroidism to euthyroid pregnant women for risk of premature delivery

$\mathrm{RR}$ : relative risk

\section{Discussion}

$\mathrm{TH}$ is an important hormone in human metabolism throughout the whole lifespan. It is a particularly important 
factor for brain development and corporal growth in the fetus. The first stage of the fetal brain growth-spurt occurs during the first and second trimesters of pregnancy. At this time $\mathrm{TH}$ is provided to the fetus mainly from transplacental delivery of THs (mainly $\mathrm{T}_{4}$ ), because fetal thyroid follicular epithelial cells are immature and cannot yet synthesize TH during the first 12 weeks of pregnancy (3). An insufficient supply of maternal THs during this period can cause significant and irreversible neurodevelopmental defects. Vulsma et al (28) showed that the umbilical cord level of $\mathrm{T}_{4}$ in fetuses with congenital hypothyroidism due to a total organification defect or thyroid agenesis was $30 \%$ to $60 \%$ that of normal fetuses, suggesting that maternal input of $\mathrm{T}_{4}$ continues until birth. Therefore, brain development during late pregnancy is driven by both fetal and maternal THs. Deficient maternal THs in late pregnancy can cause neurodevelopmental defects, although the effect may not be as serious as the impact of maternal thyroid deficiency during the first trimester of pregnancy. Children of pregnant women with overt hypothyroidism were found to have a lower level of physical and intellectual development, as well as a lower level of responsiveness to external stimuli compared with children of pregnant women with normal thyroid function $(4,5,6)$. It is unclear whether the same effect is true for children of women with $\mathrm{SCH}$. Some investigators speculate that although women with $\mathrm{SCH}$ may have normal $\mathrm{FT}_{4}$ levels, the increased $\mathrm{TSH}$ suggests these women need higher $\mathrm{TH}$ levels to ensure fetal development (29). Currently, overt hypothyroidism in pregnancy is an indication for TH replacement therapy. For women with $\mathrm{SCH}$, however, it remains unclear whether $\mathrm{TH}$ supplementation would improve the developmental status of the child. Some investigators believe that thyroxine treatment would ameliorate adverse pregnancy outcomes, and other investigators believe the contrary $(30,31)$. Our meta-analysis suggests that $\mathrm{SCH}$ is associated with delayed child intellectual and motor development, but the follow-up time of studies included in this meta-analysis was only up to two years of age, thus the impact of maternal $\mathrm{SCH}$ in the long-term was not investigated.

$\mathrm{T}_{3}$ and $\mathrm{T}_{4}$ promote the growth of long bones and teeth by stimulating the development of ossification centers. In addition, THs enhance glycogenolysis and inhibit glycogen synthesis by enhancing intestinal glucose absorption as well as by increasing glucose use by peripheral tissues. Thus, TH deficiency is a risk factor for fetal growth restriction and for LBW, both of which are risk factors for unsatisfactory neurological, motor, and intellectual development $(2,32,33)$. Ohashi et al (34) reported a probability of $25 \%$ for fetal growth restriction in pregnant women with abnormal thyroid function and a probability of $16.25 \%$ for fetal growth restriction in pregnant women with $\mathrm{SCH}$. Our study showed a 2.4-fold risk increase for fetal growth restriction in pregnant women with $\mathrm{SCH}$ as compared to pregnant women with normal thyroid function and a 1.78-fold risk for LBW. These results are consistent with those reported by Leung et al (35).

Zhang (36) reported a $6.62-7.86 \%$ incidence of abnormal thyroid function, $\mathrm{SCH}$ being the most common abnormality, prior to gestational week 20 in women without a previous history or family history of thyroid disease. $\mathrm{SCH}$ in pregnancy may be asymptomatic but, nevertheless, can negatively affect fetal neurodevelopment. Therefore, screening for thyroid abnormalities should be performed in the first trimester of pregnancy and if the TSH shows an abnormal level, more attention should be paid to the growth and development of the fetus. Some authors suggest that screening for $\mathrm{SCH}$ in pregnancy may be a cost-effective strategy in a wide range of circumstances (37). The effect of the intervention depends on the timing during gestation. Therefore, we suggest that there is an urgent need for large-scale, randomized trials to measure the intelligence of children whose mothers with $\mathrm{SCH}$ who were treated with thyroxine during pregnancy versus normal children, in theory, it should also be compared with non-intervention group, but this does not sound ethical to us, we may only be able to verify it in animal experiments.

Some studies suggest that SCH or elevated TSH in pregnancy result in premature delivery $(15,38,39)$ while other studies reached contrary conclusions $(10,19)$. Our meta-analysis showed that maternal $\mathrm{SCH}$ is associated with premature delivery. Maraka et al (14) also published a meta-analysis, showing that $\mathrm{SCH}$ during pregnancy is associated with multiple adverse maternal and neonatal outcomes. The effect of levothyroxine therapy in preventing these adverse outcomes remains uncertain. It is therefore necessary to do a large-scale trial to assess the value of levothyroxine therapy. In this study different TSH strata should be explored to identify the optimal treatment threshold, where the benefits of levothyroxine use outweigh the risks (40).

\section{Study Limitations}

The selection bias was small in this study due to a review of a vast literature and strict adherence to pre-specified inclusion and exclusion criteria. However, every metaanalysis has limitations. In our study, we did not take into account the effects of anti-thyroid antibodies, including antithyroglobulin antibodies and anti-thyroid peroxidase antibodies. As a result, we might have underestimated the effect of maternal $\mathrm{SCH}$ on growth and development or 
intelligence level. In addition, the studies included in our analysis did not provide data on family economic status, parental education level, or the environment. All of these may be confounding factors affecting child development. Also, measurement methods and measuring instruments varied across the studies included in our analysis. This, too, might have affected the results.

Our meta-analysis suggests that maternal $\mathrm{SCH}$ is associated with fetal growth restriction, impaired intellectual and motor development, LBW, premature delivery and fetal distress. Therefore, more extensive screening for thyroid function during or even prior to pregnancy may be especially important for improved outcomes. We speculate that TH supplementation may promote normal fetal development and may prevent adverse pregnancy outcomes. As this is only speculation, large-scale randomized trials are needed.

\section{Conclusion}

Our meta-analysis showed that maternal SCH in pregnancy is associated with an increased risk of several adverse neonatal outcomes. Thus, it is necessary to assess thyroid function in pregnant women and intervene when necessary. Because of the high methodological quality of the included trials, our data provide supportive evidence for initiating further investigation. Additional cohort studies including large numbers of participants are needed to guide future investigation.

\section{Acknowledgments}

This work was supported by grants from the Gansu Province Health Department (grant number: GWGL201332). We gratefully acknowledge the help of our colleagues in The Second Hospital of Lanzhou University.

\section{Ethics}

Ethics Committee Approval: All analyses were based on previous published studies, thus no ethical approval is required.

Informed Consent: All analyses were based on previous published studies, thus no patient consent are required.

Peer-review: Externally peer-reviewed.

\section{Authorship Contributions}

Concept: Hui Chen, Design: Hui Chen, Data Collection or Processing: Yahong Liu, Fupin Li, Analysis or Interpretation: Yahong Liu, Chen Jing, Literature Search: Yahong Liu, Chen Jing, Writing: Yahong Liu.

Financial Disclosure: This work was supported by grants from the Gansu Province Health Department (grant number: GWGL201332).

\section{References}

1. Ross-Flanigan N. Thyroid hormones. Encyclopedia of Medicine, 2001.

2. Lipper E, Lee K, Gartner LM, Grellong B. Determinants of neurobehavioral outcome in low-birth-weights infants. Pediatrics 1981;67:502-505.

3. Calvo RM, Jauniaux E, Gulbis B, Asuncion M, Contempre B, Morreale de Escobar G. Fetal tissues are exposed to biologically relevant free thyroxine concentrations during early phase of development. J Clin Endocrinol Metab 2002;87:1768-1777.

4. Pop VJ, Brouwers EP, Vader HL, Vulsma T, van Baar AL, de Vijlder JJ. Maternal hypothyroxinaemia during early pregnancy and subsequent child development: a 3-year follow-up study. Clin Endocrinol (Oxf) 2003;59:282-288

5. Cleary-Goldman J, Malone FD, Lambert-Messerlian G, Sullivan L, Canick J, Porter TF, Luthy D, Gross S, Bianchi DW, D'Alton ME. Maternal thyroid hypofunction and pregnancy outcome. Obstet Gynecol 2008;112:8592.

6. Zhong XM, Wu JL. Clinical analysis on maternal hypothyroidism during pregnancy. Med J West China 2008;20:604-605.

7. Zhang Y, Fan Y, Yu X, Wang X, Bao S, Li J, Fan C, Shan Z, Teng W. Maternal subclinical hypothyroidism impairs neurodevelopment in rat offspring by inhibiting the CREB signaling pathway. Mol Neurobiol 2015;52:432-441. Epub 2014 Sep 6

8. Wang S, Teng W, Gao Y, Fan C, Zhang H, Shan Z. Early levothyroxine treatment on maternal subclinical hypothyroidism improves spatial learning of offspring in rats. J Neuroendocrinol 2012;24:841-848.

9. Liu D, Teng W, Shan Z, Yu X, Gao Y, Wang S, Fan C, Wang H, Zhang H. The effect of maternal subclinical hypothyroidism during pregnancy on brain development in rat offspring. Thyroid 2010;20:909-915.

10. Saki F, Dabbaghmanesh MH, Ghaemi SZ, Forouhari S, Ranjbar Omrani G, Bakhshayeshkaram M. Thyroid function in pregnancy and its influences on maternal and fetal outcomes. Int J Endocrinol Metab 2014;12:e19378.

11. Haddow JE, Palomaki GE, Allan WC, Williams JR, Knight GJ, Gagnon J, O’Heir CE, Mitchell ML, Hermos RJ, Waisbren SE, Faix JD, Klein RZ. Maternal thyroid deficiency during pregnancy and subsequent neuropsychological development of the child. New Engl J Med 1999;341:549-555.

12. Lu XM, Chen LM, Yang H, Du WJ,Lin H,Ye EL,Zhan AX,Feng WL. Trimester specific reference data and variation of thyroid hormones for normal pregnancy. J Med Res 2012;41:70-73.

13. Stagnaro-Green A, Abalovich M, Alexander E, Azizi F, Mestman J, Negro R, Nixon A, Pearce EN, Soldin OP, Sullivan S, Wiersinga W; American Thyroid Association Taskforce on Thyroid Disease During Pregnancy and Postpartum. Guidelines of the American Thyroid Association for the diagnosis and management of thyroid disease during pregnancy and postpartum. Thyroid 2011;21:1081-1125. Epub 2011 Jul 25

14. Maraka S, Ospina NM, O’Keeffe DT, Espinosa De Ycaza AE, Gionfriddo MR, Erwin PJ, Coddington CC 3rd, Stan MN, Murad MH, Montori VM. Subclinical Hypothyroidism in Pregnancy: A Systematic Review and Meta-Analysis. Thyroid 2016;26:580-590. Epub 2016 Mar 3

15. Ajmani SN, Aggarwal D, Bhatia P, Sharma M, Sarabhai V, Paul M. Prevalence of overt and subclinical thyroid dysfunction among pregnant women and its effect on maternal and fetal outcome. J Obstet Gynaecol India 2014;64:105-110. Epub 2013 Dec 1

16. Casey BM, Dashe JS, Wells CE, McIntire DD, Byrd W, Leveno KJ, Cunningham FG. Subclinical hypothyroidism and pregnancy outcomes. Obstet Gynecol 2005;105:239-245.

17. Chen LM, Du WJ, Dai J, Zhang Q, Si GX, Yang H, Ye EL, Chen QS, Yu LC, Zhang C, Lu XM. Effects of subclinical hypothyroidism on maternal 
and perinatal outcomes during pregnancy: a single-center cohort study of a Chinese population. Plos One 2014;9:e109364.

18. Chen LM, Chen QS, Jin GX, Si GX, Zhang Q, Ye EL, Yang H, Cai LQ, Peng MM, Lin ZZ, Yu LC, Zhang C, Lu XM. Effect of gestational subclinical hypothyroidism on early neurodevelopment of offspring. J Perinatol 2015;35:678-682. Epub 2015 Jun 18

19. Sahu MT, Das V, Mittal S, Agarwal A, Sahu M. Overt and subclinical thyroid dysfunction among Indian pregnant women and its effect on maternal and fetal outcome. Arch Gynecol Obstet 2010;281:215-220. Epub 2009 May 13

20. Su PY, Huang K, Hao JH, Xu YQ, Yan SQ, Li T, Xu YH, Tao FB. Maternal thyroid function in the first twenty weeks of pregnancy and subsequent fetal and infant development: a prospective population-based cohort study in China. J Clin Endocrinol Metab 2011;96:3234-3241. Epub 2011 Aug 10

21. Wang S, Teng WP, Li JX, Wang WW, Shan ZY. Effects of maternal subclinical hypothyroidism on obstetrical outcomes during early pregnancy. J Endocrinol Invest 2012;35:322-325. Epub 2011 May 31

22. Chen G, Gao YY. The effect of subclinical hypothyroidism on fetal growth and pregnancy outcomes. Chinese Journal of Woman and Child Health Research 2013;24:698-700

23. Li JN, Zhao YC, He L, Gao XL,Wang XR,Xie Y. Influence of subclinical hypothyroidism in pregnancy on the intellectual development of their offspring and analysis of Levothyroxine intervention. Journal of China Medical University 2015;44:64-67.

24. Xia Y, Zhou YH, Zong DT, Han L, Li X, Chen FH. Impact of mental development in offspring by maternal thyroid autoimmunity and subclinical hypothyroidism in pregnancy. Journal of Clinical and Experimental Medicine 2015;14:670-672.

25. Li YB, Teng WP, Shan ZY, Zhang L, Zhao YR, Yu XH, Li YS, Wang WW, Zhao YJ, Hua TY, Yang L, Fan CL, Wang H, Guo R. Effect of maternal subclinical thyroid abnormalities on offspring's intellectual development. Chinese Journal of Endocrinology and Metabolism 2008;24:601-604.

26. Wan Y, Chen Z M. Effect of subclinical hypothyroidism on pregnancy and its outcome. Modern Medicine Journal of China 2013;15:67-68.

27. Li JM. Analysis of pregnancy outcome of pregnant women with subclinical hypothyroidism during pregnancy. Jilin Medical Journal 2016;37:1304-1306

28. Vulsma T, Gons MH, de Vijlder JJ. Maternal fetal transfer of thyroxine in congenital hypothyroidism due to a total organification defect or thyroid agenesis. N Engl J Med 1989;321:13-16.

29. Poppe K, Glinoer D. Thyroid autoimmunity and hypothyroidism before and during pregnancy. Hum Reprod Update 2003;9:149-161.
30. Lazarus JH, Bestwick JP, Channon S, Paradice R, Maina A, Rees R, Chiusano E, John R, Guaraldo V, George LM, Perona M, Dall'Amico $\mathrm{D}$, Parkes $\mathrm{AB}$, Joomun $\mathrm{M}$, Wald NJ. Antenatal thyroid screening and childhood cognitive function. N Engl J Med 2012;366:493-501.

31. Casey BM, Thom EA, Peaceman AM, Varner MW, Sorokin Y, Hirtz DG, Reddy UM, Wapner RJ, Thorp JM Jr, Saade G, Tita AT, Rouse DJ, Sibai B, Iams JD, Mercer BM, Tolosa J, Caritis SN, VanDorsten JP; Eunice Kennedy Shriver National Institute of Child Health and Human Development Maternal-Fetal Medicine Units Network. Treatment of subclinical hypothyroidism or hypothyroxinemia in pregnancy. N Engl J Med 2017;376:815-825

32. Leitner Y, Fattal-Valevski A, Geva R, Eshel R, Toledano-Alhadef H, Rotstein M, Bassan H, Radianu B, Bitchonsky O, Jaffa AJ, Harel S. Neurodevelopmental outcome of children with intrauterine growth retardation: a longitudinal, 10-year prospective study. J Child Neurol 2007;22:580-587

33. Fattal-Valevski A, Leitner Y, Kutai M, Tal-Posener E, Tomer A, Lieberman D, Jaffa A, Many A, Harel S. Neurodevelopmental outcome in children with intrauterine growth retardation: a 3-year follow-up. J Child Neurol 1999;14:724-727

34. Ohashi M, Furukawa S, Michikata K, Kai K, Sameshima H, Ikenoue T. Risk Based Screening for Thyroid Dysfunction during Pregnancy. J Pregnancy 2013;619718. Epub 2013 Mar 27

35. Leung AS, Millar LK, Koonings PP, Montoro M, Mestman JH. Perinatal outcome in hypothyroid pregnancies. Obstet Gynecol 1993;81:349353.

36. Zhang XL. Clinical Epidemiology Research of Thyroid Disease during Pregnancy. The academic dissertation of Capital Medical University 2013.

37. Thung SF, Funai EF, Grobman WA. The cost-effectiveness of universal screening in pregnancy for subclinical hypothyroidism. Am J Obstet Gynecol 2009;200:267. Epub 2008 Dec 27

38. Stagnaro-Green A, Chen X, Bogden JD, Davies TF, Scholl TO. The thyroid and pregnancy: a novel risk factor for very preterm delivery. Thyroid 2005;15:351-357.

39. Korevaar TI, Schalekamp-Timmermans S, de Rijke YB, Visser WE, Visser W, de Muinck Keizer-Schrama SM, Hofman A, Ross HA, Hooijkaas H, Tiemeier H, Bongers-Schokking JJ, Jaddoe VW, Visser TJ, Steegers EA, Medici M, Peeters RP. Hypothyroxinemia and TPO-antibody positivity are risk factors for premature delivery: the Generation R Study. J Clin Endocrinol Metab 2013;98:4382-4390. Epub 2013 Sep 13

40. Sheehan PM, Nankervis A, Araujo Junior E, Da Silva Costa F. Maternal Thyroid Disease and Preterm Birth: Systematic Review and MetaAnalysis. J Clin Endocrinol Metab 2015;100:4325-4331. Epub 2015 Sep 18 